\title{
El discurso emocional en la publicidad audiovisual de la DGT
}

\author{
Estrella MARTíNEZ RODRIGO \\ Universidad de Granada \\ emrodrigo@ugr.es \\ Rosario Segura García \\ Universidad de Granada \\ rosariosegura@ugr.es
}

Recibido: 06/11/2012

Aceptado: 23/01/2013

\section{Resumen}

Como es bien sabido, uno de los objetivos de la Dirección General de Tráfico española (DGT) es disminuir la siniestralidad tanto en las vías urbanas como en las carreteras. Afortunadamente, en la última década, se ha producido un descenso en el número de accidentes y en los índices de mortalidad de los mismos. Sin embargo, las cifras siguen siendo elevadas, fundamentalmente porque hay un porcentaje de casos que se podrían evitar con unas buenas prácticas de conducción. Una herramienta de la que dispone la DGT son las campañas de seguridad vial tanto a través de medios de comunicación -radio, carteles, televisión, Internet- como su canal de YouTube y su propia web. En este trabajo nos proponemos analizar los diferentes tipos de emociones que se representan en diferentes spots que la DGT ha promocionado en televisión y resaltar cuáles de ellas aparecen con mayor frecuencia.

Palabras clave: Emociones, Dirección General de Tráfico Española, publicidad institucional audiovisual, seguridad vial.

\section{The Emotional Speech on Audiovisual Advertising of DGT}

\begin{abstract}
As is well known, one of the objectives of the Spanish Traffic Department (DGT) is to reduce accidents in both urban roads and on highways. Fortunately, in the last decade, there has been a decline in the number of accidents and death rates thereof. However, the numbers remain high, mainly because there are a percentage of cases that could be prevented with good driving practices. One tool available to the DGT are road safety campaigns both through media-radio, billboards, television, Internet, and their YouTube channel and their own website. In this paper we analyze the different types of emotions that are represented in different spots that the DGT has promoted on television and note which ones appear more frequently.

Keywords: Emotions, Traffic Department, Audiovisual Institutional Advertising, Road Safety.

\section{Referencia normalizada}

MARTÍNEZ RODRIGO, Estrella y SEGURA GARCÍA, Rosario (2013): "El discurso emocional en la publicidad audiovisual de la DGT”. Estudios sobre el mensaje periodístico. Vol. 19. Núm. especial abril, págs.: 863-872. Madrid, Servicio de Publicaciones de la Universidad Complutense.
\end{abstract}

Sumario: 1. Introducción. 2. Objetivos y metodología. 3. Publicidad y emociones. 4. Importancia de las emociones en las campañas publicitarias de la DGT. 5. Análisis empírico; 5.1. La emoción y sus variables; 5.2. Comentario de resultados. 6. Conclusiones. 7. Referencias bibliográficas 


\section{Introducción}

La Dirección General de Tráfico ha tenido siempre como objetivo prioritario disminuir la siniestralidad en carretera. En $2012^{1}$, se ha dado la menor tasa de mortalidad, a causa de las medidas propuestas durante décadas, entre las que se incluyen las campañas publicitarias.

El objeto de la presente investigación es el recurso a las emociones que hace la DGT en los spots de las campañas publicitarias en formato audiovisual desde su origen hasta la actualidad. En este año 2012 se cumple los 50 años del primer spot televisivo.

Las emociones constituyen actualmente un tema de interés en la investigación de las ciencias sociales. En marketing y economía, en las últimas décadas, las emociones han constituido un factor a tener en cuenta para explicar conductas; incluso en ámbitos aparentemente técnicos, las emociones influyen notablemente en los resultados de ciertas acciones ${ }^{2}$.

Lógicamente en la publicidad, las emociones son un factor de persuasión clave. En este trabajo realizamos un breve análisis de cuáles son las emociones más representadas en el discurso de los spots de la DGT. Quizás, en una primera impresión, podamos pensar que son aquellas más dramáticas o dolorosas, pues son las que más impresionan, pero un análisis más detallado puede destacar otro tipo de emociones menos patentes, pero no por ello menos importantes.

\section{Objetivos y metodología}

El objetivo que nos proponemos es investigar el tipo de emociones representadas y destacar las más utilizadas en las campañas audiovisuales de la DGT desde sus comienzos. La metodología que emplearemos será la siguiente:

- elección de una muestra de spots al azar para comprobar la tendencia. El método ha sido elegir de forma aleatoria un $15 \%$ de spots de un total de 256 , es decir 39 del total;

- determinación de categorías: se han elegido el año y los tipos de emociones;

- elección de las variables de la emoción a partir de diversos estudios acerca de la naturaleza y tipología de las emociones, principalmente recogidos en Tellis y Redondo (2000), Yepes y Aranguren (2004), Oatley (1992), realizando una selección de aquellas que han aparecido en la muestra elegida

La hipótesis sobre la trabajamos es que para transmitir con más efectividad su mensaje principal de concienciar sobre la seguridad vial al ciudadano, la DGT, a lo largo de cinco décadas, ha recurrido de manera principal a emociones relacionadas con el amor entre individuos, especialmente al amor familiar.

1 DGT: nota de prensa de 3 de enero de 2012:2012 en: http://www.dgt.es/was6/portal/contenidos/documentos/prensa_campanas/notas_prensa/NotasDePrensa0152.pdf [Recuperado: 26 de enero de 2012]

2 Un ejemplo se puede observar en el estudio reflejado por Sánchez Galán (2011) acerca de las inversiones económicas y su relación con las motivaciones, en el contexto de la información periodística. 


\section{Publicidad y emociones}

Desde una perspectiva neuropsicológica, podríamos decir, con palabras del neurólogo Antonio Damasio (2003) que: "una emoción propiamente dicha, como felicidad, tristeza, vergüenza o simpatía, es un conjunto complejo de respuestas químicas y neuronales que forman un patrón distintivo. Las respuestas son producidas por el cerebro normal cuando éste detecta un estímulo emocionalmente competente, esto es, el objeto o acontecimiento cuya presencia, real o en rememoración mental, desencadena la emoción".

Desde una perspectiva sociológica e histórica, el término emoción no ha sido utilizado de modo frecuente hasta el s.XIX. Parece que fue Thomas Brown quien introdujo el uso más habitual de esta palabra (Dixon, 2003: 109-127), aunque Hume ya realiza un uso temprano del término. "Emoción" es muy utilizada en la psicología del s. XIX especialmente por William James, por Darwin y por Ernst Mach, cuyo planteamiento supone una base para entender el interés por el término emoción en la actualidad (Mach, 1987: 42).

En el siglo XX ha habido un interés creciente por el papel de las emociones en la so$\operatorname{ciedad}^{3}$. Asimismo las emociones empiezan a cobrar una gran importancia en la explicación de diversos comportamientos sociales, o incluso, dan razones de la evolución de las sociedades capitalistas (Illouz, 2009). También desde la filosofía, especialmente en el ámbito anglosajón, se ha investigado y revisado el concepto de emoción desde diversos puntos de vista (Nussbaum, 1997), (Goldie, 2000), (Kenny, 1969).

Las emociones están presentes en cada acto que llevamos a cabo, de ahí la importancia que reviste su estudio en la sociedad en general y en la publicidad en particular.

En la actualidad, economistas y científicos estudian el comportamiento del individuo centrando el peso de su conducta no tanto en lo racional sino en lo emocional. Así lo atestiguan los descubrimientos de la neurología y su aplicación al márketing, más conocidos con la denominación de Neuromárketing, que se basa en recientes estudios del cerebro sobre la comprensión del patrón inconsciente que rige el proceso de compra.

En este proceso, la combinación adecuada de imágenes publicitarias y emociones se convierte en un elemento relevante que caracteriza la comunicación de las compañías. La publicidad emocional, entendida como la persuasión dirigida a los sentimientos del público, se centra ante todo en cubrir deseos y anhelos profundos de manera real o simbólica. Un mercado de sensaciones se pone a disposición de un público que disfruta consumiendo imágenes placenteras asociadas a las marcas.

Un precedente del interés por lo emocional lo encontramos en la expresión inteligencia emocional, introducida en el campo de la psicología en 1990 por los investigadores Peter Salowey y John D. Mayer, y definida como la capacidad de percibir los sentimientos propios y los de los demás, distinguir entre ellos y servirse de esa información para guiar el pensamiento y la conducta de uno mismo.

En cuanto a la relación entre publicidad y emociones, encontramos libros que contemplan diversos elementos que vinculan ambas partes. Un buen ejemplo es $E l d i$ seño emocional, de Norman (2005), quien señala que las empresas deben ofrecer una

${ }^{3}$ Es el caso de Thomas Sheff, Arlie R. Hochschild, Theodor D. Kemper; en España, Eduardo Bericat ha realizado un análisis de esta situación. 
experiencia única a los consumidores a través de los vínculos emocionales que sean capaces de crear con los clientes para descartar a los competidores.

Kevin Roberts (2005) de Saatchi \& Saatchi, remarca la importancia de las emociones para los seres humanos. El autor de Lovemarks sostiene que hay que generar estados de ánimo a través de historias que se transmitan desde la publicidad, por lo que es fundamental la comunicación, donde las estrategias deben tener en cuenta aspectos emocionales.

En definitiva, la publicidad trabaja cada vez más en proporcionar satisfacciones y obtener resultados por la vía afectiva, en consonancia con los autores que resaltan la importancia de las emociones en las sociedades modernas. Se trata de un modo de persuasión en el que se potencia ante todo, la suscitación de emociones mediante el recurso a ellas en el discurso publicitario.

\section{Importancia de las emociones en las campañas publicitarias de la DGT}

En el caso de la Dirección General de Tráfico, la publicidad no consiste en la venta de un producto sino en la promoción de actitudes ante la seguridad vial. La disposición a acoger un mensaje se puede explicar acudiendo a la personalidad, a la actitud -tendencia adquirida mediante el aprendizaje, a responder de una manera concreta ante un objeto o situación- y a los hábitos: respuesta adquirida en el tiempo, también mediante un proceso de instrucción, concretamente a través de la repetición de los mismos actos.

Para eso, revisemos cómo actúa la publicidad sobre el público. La forma en la que se recibe un mensaje y las condiciones que afectan a su interpretación son elementos que el emisor debe tener en cuenta. En el caso de la DGT, hay que considerarlo de la misma manera: la relación entre las emociones y la publicidad viene mediada por la necesidad de persuadir e implica la intención de incidir sobre la conducta del otro. Se hace, pues, necesario acudir a ciencias como la psicología, la antropología o la retórica, que den pautas para poder ejercer una persuasión eficaz.

Una vez que el público ha recibido el anuncio, el anunciante puede valorar el efecto del impacto. La acción de informar es la más básica de la publicidad es, pero además hay que provocar una respuesta.

Tradicionalmente se considera cuatro perspectivas sobre las causas de elección de los productos:

- Apelación racional: el anuncio debe llamar la atención, despertar el interés, provocar el deseo y mover a la acción (AIDA).

- Reforzamiento de los hábitos: el beneficio del producto, el posicionamiento de la marca, los recursos utilizados para transmitir se repiten para asegurar el efecto buscado.

- Contenido sugestivo: se busca llevar una señal al inconsciente del individuo que convierta la propuesta en una opción que se adapta a su verdadera necesidad personal.

- Argumentación social: el producto o la marca se identifica con un grupo social o una serie de valores admitidos o admirados por una parte de la sociedad. Al adquirirlo se dispone de un símbolo de promoción social. 
Todas ellas suponen la existencia de un ámbito emocional en el público sobre el que hay que incidir. Y las cuatro teorías pueden explicar la necesidad de campañas publicitarias de la Dirección General de Tráfico que incidan en el ámbito de las emociones. El hilo conductor de las campañas es la seguridad vial y este mensaje con sus diversas formas de expresión ha sido transmitido durante 50 años en sus campañas publicitarias con diferente fuerza persuasiva y con un diferente recurso a emociones en el discurso audiovisual.

\section{Análisis empírico}

\subsection{La emoción y sus variables}

Entendemos por emoción por un lado un estado mental en el que suceden cambios corporales y por otro una representación de ese estado mental en la estructura cognitiva (Martínez Rodrigo y Segura García, 2011, pág. 178).

Merece la pena detenerse brevemente en la definición de las principales emociones humanas.

- Amor: es un término amplio y a nuestro juicio es algo más complejo que una emoción, pero lo incluimos aquí porque agrupa aquellas emociones que se relacionan con el afecto entre personas y que configuran algún tipo de vínculo entre ellas como el matrimonio, amor de pareja, familiar, padres e hijos, hermanos, amigos etc.

- Miedo y susto son emociones similares: el temor ante un hecho o situación. La diferencia entre ambos la situamos en que el primero es más general y permanente y el segundo es algo puntual ante un hecho determinado que acontece de modo repentino. Las agrupamos bajo el título "miedo".

- Ternura: conmoción de acercamiento ante alguien querido con manifestaciones de gestos, expresión de protección.

- Culpa: remordimiento ante una acción reprobable

- Confianza: seguridad en alguien, en algo o en sí mismo.

- Orgullo: estado de arrogancia y superioridad ante los demás.

- Sorpresa: desconcierto grato ante algo inesperado

- Alegría: estado de felicidad fisiológica y psicológica ante una situación agradable.

- Enfado: disgusto

- Valor: estado emocional que expresa fortaleza ante una dificultad

- Envidia: tristeza ante al ver algo superior en otros.

\begin{tabular}{|l|l|l|}
\hline Emociones & & $\%$ \\
\hline \multirow{3}{*}{ Amor } & Total & $\mathbf{6 0 , 5 3 \%}$ \\
\cline { 2 - 3 } & Familiar & $36,84 \%$ \\
\cline { 2 - 3 } & Otros (novios amigos) & $23,68 \%$ \\
\hline Miedo & & $39,47 \%$ \\
\hline Ternura & & $36,84 \%$ \\
\hline Culpa & & $26,32 \%$ \\
\hline Confianza & & $26,32 \%$ \\
\hline
\end{tabular}




\begin{tabular}{|l|l|l|}
\hline Orgullo & $23,68 \%$ \\
\hline Sorpresa & $18,42 \%$ \\
\hline Alegría & $15,79 \%$ \\
\hline Enfado & $10,53 \%$ \\
\hline Valor & $7,69 \%$ \\
\hline Envidia & $2,63 \%$ \\
\hline
\end{tabular}

\subsection{Comentario de resultados}

El estudio que hemos llevado a cabo acerca del recurso a emociones en el discurso audiovisual de los spots de la DGT, arrojan los siguientes resultados:

La cuantificación de estos datos lleva a pensar que en la publicidad audiovisual de la DGT, el recurso a aquellas emociones que se relacionan con el amor entre individuos $(60,53 \%)$, en especial las relacionadas con un amor de tipo familiar $(36,84 \%)$, es el más frecuente frente a otros como el noviazgo o la amistad $(23,68 \%)$.

Asimismo, arrojan resultados relativamente elevados (36-39\%) las emociones de miedo y ternura. Por debajo de ellas y con una proporción en torno al $25 \%$, destacan el orgullo, la confianza y la culpa. Por último se podrían señalar como menos frecuentes (10-18\%) el enfado y la alegría. Apenas destacarían el valor y la envidia.

En síntesis, podemos decir que la DGT tiende a estructurar su discurso audiovisual con emociones relacionadas principalmente con el amor de tipo familiar, con el miedo, ternura, orgullo, confianza y culpa.

Nos interesa detenernos en la variable que aparece con más frecuencia $(60,53 \%)$, el amor. El amor no es propiamente una emoción, de hecho, se observará que en el presente artículo, nos hemos referido a ella de diferentes maneras evitando identificar de un modo absoluto emoción y amor. Daremos algunos rasgos de lo que es el amor propiamente y lo que es una emoción para distinguirlos y señalar en qué sentido hemos utilizado el término amor.

El amor tiene que ver con el cuerpo, con los sentimientos, con los afectos, con la inteligencia y la voluntad, con toda la persona, pero la persona es realmente feliz cuando es incondicional ese amor: en la amistad, en el matrimonio y entre padres e hijos; es decir, el hombre tiene deseo de incondicionalidad.

Desde esta perspectiva, el amor no es un sentimiento o una emoción sino que ambos pueden formar parte del amor, de manera que cuando hay amor, ciertas emociones se conjugan junto con otras dimensiones del individuo para dar como resultado una forma de deseo y un darse con rasgo de incondicionalidad. Y por tanto la pérdida del objeto amado es traumática.

Más arriba recogíamos la definición del amor que da Damasio, pero el amor es algo más complejo que no puede definirse con dichas palabras; una emoción puede ser parte del amor, pero el amor no es una emoción propiamente dicha, y el rasgo que más netamente lo diferencia es justamente su carácter de incondicionalidad, ya que de por sí la emoción está sujeta al espacio y al tiempo, y por eso mismo no puede ser incondicional.

Si observamos los spots de la DGT veremos diversas formas de amor: amor de padres a hijos, de hermanos, de marido y mujer, de amigos, o de pareja. Y la ruptura que 
supone el fallecimiento de un ser querido. Los sentimientos que afloran son el dolor, la angustia, la pena o, si se trata de una lesión grave, la compasión; se nos describe con detalle, cómo cambia la vida. Y este aspecto es muy relevante en el amor: cuando dos se aman, la vida no es igual cuando uno desaparece ${ }^{4}$.

En concreto, resultan muy significativos los spots del año 1995. En ellos de una manera sencilla, bajo el título: "Cuando se comete una imprudencia, muchos inocentes pagan por ella", se reflejan los diferentes lazos familiares entre padres, hijos, hermanos, abuelos, tíos y sobrinos. Los ejemplos de dolor que se exponen son variados y algunos, podríamos decir, muy físicos y psicológicos, al estilo de Damasio, pero otros son difíciles de calificar como físicos, pues reflejan la ausencia de un individuo: aquellas cosas que deja de hacer junto a otros, es decir, lo que cambia la vida de una persona ante la pérdida de un ser querido; es como ver en negativo, lo que es el amor: un conjunto de cosas sencillas.

Se trata de una serie de 7 spots $^{5}$ con el mismo esquema narrativo:

- voz en off presentando a diferentes personajes, mediante su imagen en una fotografía, y comenta brevemente la relación con el fallecido, repitiendo el verbo "perder";

- tras esa presentación, texto escrito con la consecuencia del hecho para cada personaje;

- por último, el eslogan en voz en off, y en texto escrito el verbo "piénsalo", interpelando al espectador en singular;

- de fondo, música similar a una canción de cuna.

Tomemos como modelo el spot número 5 de la serie. El texto hablado y escrito es el siguiente:

\begin{tabular}{|l|r|}
\hline Andrés ha perdido a su hijo en un accidente de circulación & voz en off \\
\hline ya no tiene fuerzas para ir a trabajar & texto escrito \\
\hline María, ha perdido a su marido & voz en off \\
\hline sufrió un infarto al recibir la noticia & texto escrito \\
\hline Marta ha perdido a su padre & voz en off \\
\hline no puede entender por qué su vida ha cambiado tanto & texto escrito \\
\hline $\begin{array}{l}\text { Nada de esto estaría sucediendo si el vehículo que arrolló a David hubiera respetado } \\
\text { la distancia de seguridad. Cuando se comete una imprudencia, muchos inocentes } \\
\text { pagan por ella }\end{array}$ & voz en off \\
\hline Piénsalo & texto escrito \\
\hline
\end{tabular}

Aparecen narrados aspectos psicológicos (ya no tiene fuerzas para ir a trabajar), físicos (infarto), o existenciales (no entiende...). Los lazos familiares que aquí se mues-

${ }^{4}$ Resulta muy ilustrativo la descripción que realiza Ch. S. Lewis en su ensayo Una pena en observación. En él se describe maravillosamente lo que supone para el autor la pérdida de su mujer, y cómo cambia el universo a su alrededor.

${ }_{5}^{5}$ Disponibles en http://www.dgt.es/was6/portal/contenidos/visor_multimedia/\#app=7f51 $\&$ f94f-selectedIndex $=0$ 
tran son: padres-hijos, marido-mujer; la música acentúa la ternura de los vínculos familiares, invitando al espectador a concluir el destrozo que supone un accidente y más si es por una imprudencia. En negativo, se representa lo que es el amor entre estos personajes, es decir a través del dolor, se representa el amor: el motor para trabajar, su relación con la salud, y el sentido de la vida.

Otro spot significativo es el de Navidad del año 2004, con el eslogan: "Tú eres el mejor regalo para los que te esperan". En él se puede ver a un hombre conduciendo mientras se intercalan imágenes de lo que ocurre en su hogar: su mujer preparando la mesa de la cena de Navidad, su hija poniendo bolas en el árbol. Y finalmente una voz femenina que repite el eslogan. Se está narrando el amor como una espera de algo que se quiere.

¿Por qué hemos querido tipificar el amor de manera simétrica a otras emociones? Porque engloba un conjunto de emociones dispuestas de una manera peculiar, y ya en este sentido, ese conjunto de emociones con tal disposición, ya representan algo diferente que una emoción simple como el miedo o el odio.

Lo que resulta llamativo es la frecuencia con la que se representa el amor en sus diversas maneras, en dichos spots y su duración en el tiempo: 50 años. Especialmente es llamativa la representación del amor familiar: padres, hijos, abuelos y hermanos, repetida constantemente en todas las décadas. Pensamos que la causa es la seguridad de su eficacia, que no puede venir de otro sitio que de la realidad social misma a la que se dirigen los spots.

\section{Conclusión}

La conclusión a la que llegamos es que se confirma la hipótesis de trabajo inicial, o dicho en otras palabras: las emociones más representadas son las vinculadas a relaciones de afecto conocidas como amor entre individuos especialmente en relaciones de tipo familiar.

Pero más interesante todavía es comprobar que el resto de las emociones aparecen fuertemente ligadas a ese afecto entre personas: en positivo, por tenerlas cerca, o en negativo por la posibilidad de perderlas.

La alta frecuencia del recurso a estas emociones en el discurso de los spots de la DGT se deriva de que son las que mejor reflejan lo más netamente importante para la persona humana: la pérdida de aquellos a quienes ama, en este caso, como consecuencia de la violación de las indicaciones sobre seguridad vial.

Pero además se está reflejando una realidad social, no solo personal. El hecho de que este mensaje esté presente a lo largo de los 50 años de existencia de la DGT, sin que apenas se haya modificado esta concepción, acentúa la importancia de los vínculos familiares en la sociedad española.

Por otro lado, si se recurre a estas representaciones es porque se está seguro de su efectividad, más aún tratándose del interés por evitar sufrimiento y muerte; es decir, que la DGT recurre a lo que con certeza va a llegar al público, y con lo que más rápidamente se puede identificar el espectador.

Aunque parece una conclusión obvia, resalta el hecho de que a niveles de investigación teórica, tanto en ciencias sociales como humanas se asegura con frecuencia el 
cambio en las concepciones de la sociedad acerca de términos como familia, roles, hombre, mujer; sin embargo, a nivel práctico, vital, la publicidad de la DGT nos ha mostrado una interesante permanencia.

\section{Referencias bibliográficas}

DAMASIO, Antonio (2003): En busca de Spinoza, neurobiología de la emoción y de los sentimientos. Barcelona, Crítica.

DGT: Nota de prensa de 3 de enero de 2012, en: http://www.dgt.es/was6/portal/contenidos/documentos/prensa_campanas/notas_prensa/NotasDePrensa0152.pdf

DIXON, Thomas (2003): From Passions to emotions. Cambridge, Cambridge University Press.

GOLDIE, Peter (2000): Las emociones: una exploración filosófica. Oxford, Clarendon Press.

ILLOUZ, Eva (2009): El consumo de la utopía romántica. Barcelona, Katz.

KENNY, Anthony (1969): Action, emotion and will. London, Routledge \& Kegan Paul.

LEWIS, Clive Styples (1994): Una pena en observación. Madrid, Anagrama.

MACH, Ernst (1987): Análisis de las sensaciones. Barcelona, Alta Fulla.

MARTÍNEZ RODRIGO Estrella, SEGURA GARCÍA, Rosario y SÁNCHEZ MARTÍN, Lourdes (2011): "El complejo mundo de la interactividad: emociones y redes sociales". Revista Mediterránea de Comunicación, año 2, pp. 171-190, disponible en http://www.rmedcom.org/2011/1110/1110Martinez.pdf [Consultado: 29 de septiembre de 2012]

NORMAN, Donald (2005): El diseño emocional. Barcelona, Paidós.

NUSSBAUM, Martha (1997): Justicia poética. Barcelona, Andrés Bello.

OATLEY, Keith (1992): Best Laid Schemes: The Psychology of Emotions. Cambridge, Cambridge University Press.

ROBERTS, Kevin (2005): Lovemarks: el futuro más allá de las marcas. Madrid, Empresa Activa.

SÁNCHEZ GALÁN, Jose Ramón (2011): "The credibility of the information of Financial journalism". Estudios sobre el mensaje periodístico, vol. 17, Num.2, disponible en http://revistas.ucm.es/index.php/ESMP/article/view/38135/36887 [Consultado: 29 de septiembre de 2012]

SPANG, Kurt (2009): Persuasión. Fundamentos de retórica. Pamplona, Eunsa.

TELLIS, Gerard y REDONDO, Ignacio (2000): Estrategias de publicidad y promoción. Madrid, Pearson Education.

YEPES, Ricardo y ARANGUREN, Javier (2004): Fundamentos de antropología humana. Pamplona, Eunsa. 


\section{Dra. Estrella MARTÍNEZ RODRIGO}

Universidad de Granada

Facultad de Comunicación y Documentación.

Profesora de Comunicación audiovisual y Publicidad

emrodrigo@ugr.es

\section{Rosario SEGURA GARCÍA}

Universidad de Granada

Facultad de Comunicación y Documentación

Investigadora de Comunicación Audiovisual y Publicidad

rosariosegura@ugr.es 